http://jmscr.igmpublication.org/home/

ISSN (e)-2347-176x ISSN (p) 2455-0450

crossref DOI: https://dx.doi.org/10.18535/jmscr/v8i6.56

Journal Of Medical Science And Clinical Research

\title{
Third Trimester Bleeding: It's Effect on Foetal Outcome -A Study at Tertiary Care Hospital
}

\author{
Authors
}

\section{Dr Naveen Kumar*, Dr Sanjana Jourwal, Dr R P Rawat}

Department of Obstetrics \& Gynecology, Govt. Medical College \& Associated Group of Hospitals, Kota,

Rajasthan, India

*Corresponding Author

Dr Naveen Kumar

Goyal Medical Store, Kumher road, Nadbai, Bharatpur (Rajasthan), India

\begin{abstract}
Objective: To evaluate the foetal morbidity and mortality in relation to various causes of third trimester bleeding at J K Lon hospital, kota (Rajasthan).

Methods: 312 pregnant women of third trimester bleeding, coming to OPD were recruited for study after applying inclusion \& exclusion criteria in our institute during the period of $1^{\text {st }}$ March 2018 to $28^{\text {th }}$ February 2019. Their foetal outcome is observed, compiled, analysed and evaluated.

Results: Out of the 314 babies delivered (including two twins), 258 were alive at birth while 56 were dead. Thus overall Still birth rate was $17.83 \%$ (56 out of 314 cases) or 217/1000 live birth. Maximum still births were in abruption group which was 27.22\%. Out of 258 alive births, 45 dies in early neonatal period. Maximum death in early neonatal period occur in abruption group was $22.13 \%$.

Among the 314 babies, perinatal death rate is $32.17 \%$ (101 out of 314 cases), among them maximum in abruption cases which was $43.33 \%$, followed by indeterminate group $25 \%$, and minimum in placenta previa group which was $14.29 \%$.

Prematurity is the most common complication accounting for $57.75 \%$ Cases. Among abruption group $66.41 \%$ babies were premature followed by $52.94 \%$ in indeterminate group and $47.31 \%$ in placenta previa group.

Conclusion: Abruptio placentae remains important cause of perinatal morbidity and mortality in third trimester bleeding.

Keywords: Antepartum hemorrhage, Placenta previa, Abruptio placentae.
\end{abstract}

\section{Introduction}

Obstetric hemorrhage is the most common cause of maternal morbidity and mortality and is also a major cause of perinatal morbidity and mortality. Among Obstetric hemorrhage cases, third trimester bleeding is the most common cause of maternal mortality accounting for half of the deaths. Third trimester bleeding is defined as any bleeding from or into the genital tract after the period of viability, 28 weeks in India and before the end of second stage of labour, It is also called as antepartum hemorrhage. It complicates about 2$5 \%$ of all the pregnancies. It can be due to placenta previa, abruptio placentae, indeterminate cause or local causes of genital tract. It is one of grave obstetrical emergency and fear to pregnant 
women, challenge to obstetrician and is a concern for patients and her doctor.

APH is responsible for $15 \%$ of perinatal deaths. In contrast to placental abruption, placenta previa is less commonly associated with perinatal loss. Various foetal complications are prematurity, low birth weight, FGR, intrauterine death, malpresentation, congenital malformation and birth asphyxia. Perinatal mortality is less than 10 per 1000 total births in developed countries while it is much higher in India 28/1000 total births ${ }^{1}$. In developing countries widespread preexisting anemia, difficulties with transport, restricted medical facilities, decreased awareness on part of patient and relatives are largely responsible for high MMR and perinatal mortality. Although third trimester bleeding cannot be prevented but perinatal and maternal morbidity and mortality associated with it can be reduced significantly by aggressive expectant management.

Presently increasing use of trans abdominal sonography / trans vaginal sonography for placental localization and detection of abruption, improved obstetric and anaesthetic facilities, increasing use of blood and its products to correct anemia and advanced neonatal care facilities to make increased chances of survival of a preterm infant. All collectively have played important role in decreasing perinatal as well as maternal morbidity and mortality. This study was done to evaluate how far we have come and the effect of such treatment on the perinatal outcome. The foetal outcome will be assessed in terms of birth status, APGAR score at birth, birth weight, gestational age and early neonatal complications.

\section{Material and Methods}

This study was a prospective observational study undertaken during a period of one year from $1^{\text {st }}$ March 2018 to 28 Feb 2019 in J K Lon Hospital, Kota. There were 312 pregnant women cases found with third trimester bleeding out of 11202 total deliveries.

All pregnant women booked or unbooked coming with complaint of bleeding per vaginum with gestational age $>28$ weeks were included in study and pregnant women coming with complaint of bleeding per vaginum with gestational age $<28$ weeks, patients suffering from any other bleeding disorder, bleeding from a source other than uterus (Example - cervical polyp, cervical erosion, $\mathrm{Ca}$ cervix, coital injury, local trauma etc) were excluded.

Patients with bleeding per vaginum $>28$ weeks who were admitted in the hospital and who met the inclusion criteria were noted. Gestational age was calculated from the last menstrual period or earlier scans. After taking thorough history, general physical examination and obstetrical examination was carried out including foetal heart sound assessment.

Blood samples were obtained for lab investigations (blood grouping, complete hemogram, RFT, LFT, coagulation profile etc) and cross matching. USG was done to establish the cause of APH, when maternal and foetal conditions were stable and findings were noted in relation to Gestational age, Placental site, Retroplacental hematoma and Placental separation.

The data was collected using a prepared proforma meeting the objectives of the study, this data was compiled and analysed on the basis of various causes of APH and its association with the following foetal outcomes was evaluated.

\section{Foetal Outcomes}

- Prematurity

- Low Apgar Score

- Neonatal Jaundice

- Respiratory distress

- Meconium aspiration

- Perinatal mortality (Stillbirth, Early Neonatal / Newborn deaths within first week)

These particular outcomes are chosen because of existing evidence of their association with Ante Partum Hemorrhage.

\section{Results}

In the study period spanning from $1^{\text {st }}$ March 2018 to $28^{\text {th }}$ February 2019 , the total number of deliveries conducted were 11,202. Among them 
6,082 cases were delivered vaginally and 5,120 cases were delivered by cesarean Section. After applying inclusion and exclusion criteria there were 312 cases of third trimester bleeding noted and then evaluated as per various cause of APH and evaluation of 314 babies done, born to these mothers including two twins one in placenta previa and one in abruption. In the study period we encountered 312 cases of third trimester bleeding, giving an incidence of 2.79 percent. Incidence of abruptio placentae, placenta previa and indeterminate causes is thus calculated $1.60 \%$, $0.87 \%$ and $0.32 \%$ respectively.

Out of the 314 babies delivered, 258 were alive at birth while 56 were dead. Thus overall still birth rate was $17.83 \%$ (56 out of 314 cases) or $217 / 1000$ live birth. Maximum still birth were in abruption group which was $27.22 \%$. Among 258 live births, 45 dies in early neonatal period. Thus perinatal death rate is $32.17 \%$ (101 out of 314 cases), maximum in abruption cases which was $43.33 \%$, followed by indeterminate group $25 \%$, and minimum in Placenta previa group which was $14.29 \%$. hence previa group had better survival chances for 84 babies out of 98 birth.

Data Analysis shows that a total of 208 babies delivered with low birth weight giving an incidence of $66.24 \%$ while 55 babies out of 314 have very low birth weight (Birth weight less than $1.5 \mathrm{~kg}$ ) giving an incidence of $17.51 \%$. Incidence of low birth weight was $69.44 \%$, $64.29 \%$ and $55.56 \%$ in abruption, previa and indeterminate group respectively while incidence of very low birth weight was $22.45 \%, 15.56 \%$, and $13.88 \%$ in previa, abruption and indeterminate group respectively.

There was $58.42 \%$ incidence of perinatal death in 28-32 weeks gestation group (59 out of 101 cases), followed by $35.64 \%, 5.94 \%$ in $33-36$ weeks and 37-40 weeks gestation group respectively. Its incidence approx equally in abruption, previa and indeterminate group. Incidence of stillbirth was $60.71 \%, 35.71 \%$ and $3.57 \%$ in $28-32$ weeks, 33-36 weeks and $37-40$ weeks group respectively.

Taken the apgar score less than 7 as a definition for foetal asphyxia, data indicates that $45.35 \%$ newborns were asphyxiated at 1 minute while after initial resuscitation $20.93 \%$ remained still asphyxiated at 5 minutes and subjected for further resuscitation in NICU. If we evaluate the data group wise it is revealed that $26.71 \%$ in abruption group, $10.75 \%$ in previa group and $26.47 \%$ in indeterminate group remained asphyxiated at 5 minutes after birth and admitted in NICU.

Data analysis shows that prematurity is the most common complication account for $57.75 \%$ Cases. Among abruption group $66.41 \%$ babies were premature followed by $52.94 \%$ in indeterminate group and $47.31 \%$ in placenta previa group. Neonatal jaundice is the $2^{\text {nd }}$ common complication account for $17.82 \%$ cases. Respiratory distress accounts for $14.34 \%$ cases and meconium aspiration accounts for $6.20 \%$ cases.

Table: 01 Distribution of Perinatal outcome according to cause of APH

\begin{tabular}{lcccc}
\hline & $\begin{array}{c}\text { Abruptio } \\
\text { Placentae }\end{array}$ & Placenta Previa & Indeterminte Cause & Total \\
\hline Baby birth & 180 & 98 & 36 & $\mathbf{3 1 4}$ \\
Live Born & 131 & 93 & 34 & $\mathbf{2 5 8}$ \\
IUD / Still Birth & 49 & 05 & 02 & $\mathbf{5 6}$ \\
Early Neonatal Death & 29 & 09 & 07 & $\mathbf{4 5}$ \\
Perinatal Death & 78 & 14 & 09 & $\mathbf{1 0 1}$ \\
\hline
\end{tabular}




\section{JMSCR VoI||08||Issue||06||Page 288-293||June}

Table: 02 Distribution of babies as per Birth Weight according to cause of APH

\begin{tabular}{lcccc}
\hline Baby Birth Weight & $\begin{array}{c}\text { Abruptio } \\
\text { Placenta }\end{array}$ & Placenta Previa & $\begin{array}{c}\text { Indeterminte } \\
\text { Cause }\end{array}$ & Total \\
\hline $\begin{array}{l}<1.5 \text { Kg } \\
\text { (Very Low Birth Wt.) }\end{array}$ & 28 & 22 & 05 & $\mathbf{5 5}$ \\
$\begin{array}{l}\text { 1.5 - 2.49 Kg } \\
\text { (Low Birth Wt) }\end{array}$ & 97 & 41 & 15 & $\mathbf{1 5 3}$ \\
$\geq 2.5$ Kg & 55 & 35 & 16 & \\
Total & $\mathbf{1 8 0}$ & $\mathbf{9 8}$ & $\mathbf{3 6}$ & $\mathbf{3 1 4}$ \\
\hline
\end{tabular}

Table: 03 APGAR Score in live born babies (258 Live Birth)

\begin{tabular}{llcccc} 
& Apgar Score & Abruptio Placentae & $\begin{array}{c}\text { Placenta } \\
\text { Previa }\end{array}$ & $\begin{array}{c}\text { Indeterminte } \\
\text { Cause }\end{array}$ & Total \\
\cline { 2 - 6 } At 1 Min. & $<7$ & 66 & 37 & 14 & $\mathbf{1 1 7}$ \\
& $\mathbf{7 - 1 0}$ & 65 & 56 & 20 & $\mathbf{1 4 1}$ \\
At 5 Min. & $<7$ & 35 & 10 & 09 & $\mathbf{5 4}$ \\
& $\mathbf{7 - 1 0}$ & 96 & 83 & 25 & $\mathbf{2 0 4}$ \\
\hline
\end{tabular}

Table: 04 Distribution of perinatal outcome according to POG at delivery as per cause of APH

\begin{tabular}{|c|c|c|c|c|c|}
\hline & $\begin{array}{l}\text { Abruptio } \\
\text { Placentae }\end{array}$ & $\begin{array}{c}\text { Placenta } \\
\text { Previa }\end{array}$ & $\begin{array}{l}\text { Indeterminte } \\
\text { Cause }\end{array}$ & Total & \\
\hline Still Birth \& IUD & 30 & 02 & 02 & 34 & \\
\hline Perinatal Death & 46 & 08 & 05 & 59 & 28-32 Weeks \\
\hline Still Birth \& IUD & 17 & 03 & 00 & 20 & \\
\hline Perinatal Death & 28 & 05 & 03 & 36 & 33-36 Weeks \\
\hline Still Birth \& IUD & 02 & 00 & 00 & 02 & \\
\hline Perinatal Death & 04 & 01 & 01 & 06 & 37-40 Weeks \\
\hline Total (SB/PND) & $49 / 78$ & $05 / 14$ & $02 / 09$ & $56 / 101$ & \\
\hline
\end{tabular}

Table: 05 Distribution of neonatal Complications according to cause of APH

\begin{tabular}{lcccc}
\hline & $\begin{array}{c}\text { Abruptio } \\
\text { Placentae (131) }\end{array}$ & $\begin{array}{c}\text { Placenta Previa } \\
(\mathbf{9 3})\end{array}$ & Indeterminte Cause (34) & $\begin{array}{c}\text { Total } \\
(\mathbf{2 5 8})\end{array}$ \\
\hline Prematurity & 87 & 44 & 18 & $\mathbf{1 4 9}$ \\
Respiration Distress & 19 & 09 & 09 & $\mathbf{3 7}$ \\
Meconium Aspiration & 13 & 02 & 01 & $\mathbf{1 6}$ \\
Neonatal Jaundice & 22 & 13 & 11 & $\mathbf{4 6}$ \\
\hline
\end{tabular}

\section{Discussion}

Antepartum hemorrhage still ranks one of the gravest obstetric emergencies. Even with the best obstetric care due to dramatic suddenness, a pregnant woman can become exsanguinated due to bleeding in third trimester of pregnancy. It is one of the major causes of maternal \& foetal morbidity and mortality throughout the world, occurring in 3 to 4 percent of all pregnancies.

$>$ The incidence of antepartum haemorrhage in our study is $2.79 \% \quad(312 / 11,202$ Deliveries). The incidence observed by 
Menon and Sokhi $\mathrm{KK}^{2}$ from India was $2.7 \%$ and by Arora $\mathrm{R}^{3}$ from India was $2.5 \%$. Thus incidence of APH in this study was found to be similar to other Indian studies. In a study done by Kwawukume ${ }^{4}$, the incidence of $\mathrm{APH}$ was found to be $1.2-1.8 \%$. It was reported to be $1.6 \%$ by Bako, et $\mathrm{al}^{5}$. and Adegbola ${ }^{6}$ reported a lowest incidence of APH of $0.2 \%$.

In the present study, $82.17 \%$ of the patients with antepartum hemorrhage had live births, $17.83 \%$ (56/314) had either intrauterine death or stillbirth and $17.44 \%$ (45/258) had early neonatal deaths. This was comparable to the study by Jaju KG, et al., where $45.5 \%$ had either intrauterine death or still birth, and $4.5 \%$ were neonatal deaths ${ }^{7}$. Mukherjee, et al. reported higher (67.9\%) still births or intra uterine deaths and Purohit A, et al. reported only $15.6 \%$ of IUD or still birth. Purohit A, et al. also reported $7 \%$ of neonatal deaths which was comparable to the present study $^{8}$. In the abruption group $72.78 \%$ and placenta previa $94.90 \%$ were live births. This was in contrast to Bako, et al. study where $61 \%$ of the births in patients with abruption were dead born ${ }^{5}$. However, only $10 \%$ of the births in patients with placenta previa were dead born in the same study.

In the present study, $66.24 \%$ of the births had birth weight $<2.5 \mathrm{Kg}$, lower to the study by Bhandiwad, et al. ${ }^{9}$ in which $85 \%$ of the births had wt $<2.5 \mathrm{Kg}$. Arora, et al. showed little low incidence compared to the above study where $67 \%$ had birth weight $<2.5 \mathrm{Kg}$. Contrary to the above study Adekanle, et al. only $25 \%$ had birth weight $<2.5 \mathrm{Kg}^{10}$. In the present study, babies had low birth weight because of pre-eclampsia association in the mother and also due to prematurity.

In the present study, 45.35\% (117/258 cases) with APH had an APGAR score $<7$ at one minute. The study conducted by Adekanele, et al. ${ }^{10}$ reported that $61.1 \%$ of babies in APH group had APGAR score of $<7$ at one minute. $61.1 \%$ had an APGAR score of $>7$ at 5 minutes. In patients with antepartum hemorrhage majority $79.07 \%$ had APGAR score $>7$ in the present study.

$>$ One of the major aspects of this study was to study the perinatal outcome in various groups of APH. Prematurity was the most common complication in APH, followed by Neonatal jaundice and birth asphyxia. In the present study $14.34 \%$ had respiratory distress comparable to $3 \%$ in the study by Jaju KG, et al. In present study physiological jaundice was high (17.83\%) because of prematurity .Contrary to this only $7.58 \%$ in study by Jaju KG, et al. had jaundice. Prematurity was seen in $57.75 \%$ in this study contrary to which $25.76 \%$ in Jaju $\mathrm{KG}$, et al. had prematurity ${ }^{7}$.

\section{Conclusion}

From the present study it can be concluded that antepartum hemorrhage is still a leading cause of perinatal morbidity and mortality in our country. The commonest cause of antepartum hemorrhage was placental abruption followed by placenta previa.

In abruption group foetal morbidity and mortality was also high when compared to placenta previa group. This was because most of the cases in abruption group presented late and already had complications at the time of admission, while in placenta previa group diagnosis was made early by ultrasound before they became symptomatic clinically, So they were carefully managed. perinatal mortality is high because of prematurity. Routine antenatal check-up, timely referral, timely cesarean section and wider acceptance of expectant line of management in tertiary centre with availability of good neonatal intensive care unit will help further to lower the perinatal morbidity and mortality.

Conflicts of interest and source of funding: None 


\section{References}

1. Park K. Maternal and child health. In: Park's textbook of preventive and social medicine. 23rd edition. Banarasi Das Bhanot 'Jabalpur; 2015.

2. Menon kk, Sokhi KK. Accidental hemorrhage in teaching hospital. J Obstet Gynaecol 1961; 11: 335-41.

3. Arora R, Devi U, Majumdar K. Perinatal morbidity and mortality in antepratum hemorrhage. J Obstet Gynaecol India 2001; 51 (3): 102.

4. Kwawukume E.Y. Antepartum haemorrhage. Comprehensive Obstetric in the Tropics, first edition. Edited by E. Y. Kwawukume and E. E. Emuveyan. Asante and Hittscher printing press limited (Dansoman), 2002, p. 140, 150.

5. B. Bako, B. M. Audu, C. M. Chama, O. Kyari, A. Idrissa. A 8 year clinical review of antepartum hemorrhage 1999-2006 ; BOMJ, 2008; 5(2): 14-21.

6. RO Adegbola, AA Okunowo. Pattern of antepartum hemorrhage at the Lagos teaching hospital, Lagos, Nigeria. African journals online, 2009; 56(1).

7. Kalavati Girdharilal Jaju, A P Kulkarni, Shivprasad Kachrulal Mundada. Study of perinatal outcome in relation to APH. International Journal of Recent Trends in Science and Technology, 2014; 11(3): 355-358.

8. Purohit A, Desai R, B.S. Jodha, Garg B. Maternal and foetal outcome in third trimester bleeding. JOSR journal of dental \& medical sciences, 13(5): 13-16.

9. Ambarisha Bhandiwad, Abhishek A. Bhandiwad. A study of maternal and foetal outcome in Antepartum haemorrhage. Journal of evidence based medicine and healthcare, 2014; 1(6): 406-427.
10. Adekanle D, Adeyemi A, Fadero F. Antepartum hemorrhage and pregnancy outcome in Lautech Teaching Hospital, southwestern Nigeria, Journal of Medicine and Medical Sciences, 2011; 2(12): 12431247. 